\title{
Physiological predictors of survival in patients with sarcoidosis-associated pulmonary hypertension: results from an international registry
}

\author{
Oksana A. Shlobin ${ }^{1}$, Vasilis Kouranos ${ }^{2}$, Scott D. Barnett ${ }^{1}$, Esam H. Alhamad ${ }^{3}$, \\ Daniel A. Culver ${ }^{4}$, Joseph Barney ${ }^{5}$, Francis C. Cordova ${ }^{6}$, Eva M. Carmona7, \\ Mary Beth Scholand $\mathbb{0}^{8}$, Marlies Wijsenbeek ${ }^{9}$, Sivagini Ganesh ${ }^{10}$, Elyse E. Lower ${ }^{11}$, \\ Peter J. Engel ${ }^{12}$, John Wort ${ }^{2}$, Laura Price ${ }^{2}$, Athol U. Wells², Steven D. Nathan ${ }^{1}$ \\ and Robert P. Baughman ${ }^{11}$
}

@ERSpublications

Decreased 6-min walk distance and reduced diffusion capacity are associated with decreased survival in patients with sarcoidosis-associated pulmonary hypertension http://bit.ly/2UQfWJh

Cite this article as: Shlobin OA, Kouranos V, Barnett SD, et al. Physiological predictors of survival in patients with sarcoidosis-associated pulmonary hypertension: results from an international registry. Eur Respir J 2020; 55: 1901747 [https://doi.org/10.1183/13993003.01747-2019].

\begin{abstract}
Introduction: Sarcoidosis-associated pulmonary hypertension (SAPH) is associated with reduced survival in single-centre studies. The international Registry for SAPH (ReSAPH) with long-term follow-up was established to enrich our knowledge of this complication of sarcoidosis. This analysis aims to elucidate factors associated with reduced transplant-free survival in SAPH patients.

Methods: ReSAPH contains prospectively collected outcomes of SAPH patients since the time of registry enrolment. Information analysed includes right heart catheterisation data, pulmonary function testing, chest radiography, Scadding stage and 6-min walk distance (6MWD), among others. Cox regression models were used to identify independent predictors of transplant-free survival.

Results: Data from 215 patients followed for a mean \pm SD $2.5 \pm 1.9$ years were available for analysis. In the 159 precapillary patients, the Kaplan-Meier-adjusted 1-, 3- and 5-year transplant-free survival was $89.2 \%$, $71.7 \%$ and $62.0 \%$, respectively. Kaplan-Meier-adjusted 1-, 3- and 5-year transplant-free survival in the incident group was $83.5 \%, 70.3 \%$ and $58.3 \%$, respectively, and in the prevalent group was $94.7 \%, 72.2 \%$ and $66.3 \%$, respectively. Patients with reduced diffusing capacity of the lung for carbon monoxide $\left(D_{\mathrm{LCO}}\right)$ $(<35 \%$ predicted) and $6 \mathrm{MWD}<300 \mathrm{~m}$ in the precapillary cohort had significantly worse transplant-free survival. Reduced 6MWD and preserved forced expiratory volume $\left(\mathrm{FEV}_{1}\right) /$ forced vital capacity (FVC) ratio were identified as independent risk factors for reduced transplant-free survival in the precapillary cohort. Conclusion: Reduced $D_{\mathrm{LCO}}(<35 \%$ pred) and $6 \mathrm{MWD}(<300 \mathrm{~m})$ at the time of registry enrolment were associated with reduced transplant-free survival in the overall precapillary cohort. Preserved $\mathrm{FEV}_{1} / \mathrm{FVC}$ ratio was identified as an independent risk factor for worsened outcomes.
\end{abstract}

\footnotetext{
This article has an editorial commentary: https://doi.org/10.1183/13993003.00700-2020

This study is registered at www.clinicaltrials.gov with identifier number NCT01467791.

Received: 13 Feb 2019 | Accepted after revision: 11 Feb 2020

Copyright OERS 2020
} 


\section{Introduction}

Sarcoidosis is a multisystem disease prevalent throughout the world [1, 2]. Lung involvement in sarcoidosis is seemingly invariable, with up to $95 \%$ of patients manifesting some form of pulmonary disease during the course of their lifetime. Sarcoidosis-associated pulmonary hypertension (SAPH) is a complication associated with significant morbidity and increased mortality [3].

From 2010 to 2013, the reported incidence of sarcoidosis in the Unites States ranged between 7.6 and 8.4 per 100000 insured patients with an expected prevalence of $\sim 60.0$ per 100000 [4]. The reported prevalence of SAPH is between $6 \%$ and $20 \%$ at rest and up to $43 \%$ with exercise $[3,5-9]$, with rates of $75 \%$ in those listed for lung transplantation [4].

SAPH is categorised as group 5 pulmonary hypertension $[10,11]$. Although SAPH occurs more frequently in patients with fibrotic disease, it has been described in those without parenchymal involvement [12]. In addition to fibrotic distortion of the pulmonary vasculature from parenchymal fibrosis, other factors may be related to the granulomatous changes of the pulmonary vasculature found on both arterial and venous sides. Additionally, extrapulmonary factors such as extrinsic mechanical compression of the large pulmonary arteries by hilar lymphadenopathy or fibrosing mediastinitis may play a role, as well as their associated comorbidities, including obstructive sleep apnoea, liver disease and heart failure [13].

Since SAPH is relatively rare, the most practical way to further explore this previously underappreciated entity is through the inception of prospective registries. Therefore, an observational international Registry for Sarcoidosis Associated Pulmonary Hypertension (ReSAPH) was established to prospectively collect data on patients with both incident and prevalent SAPH. We have previously reported the baseline characteristics of the ReSAPH population [14] and now provide an analysis of outcomes for the precapillary subset of patients.

\section{Materials and methods}

Patients with a diagnosis of sarcoidosis based on the American Thoracic Society/European Respiratory Society (ERS)/World Association of Sarcoidosis and Other Granulomatous Diseases criteria [15], data from at least one follow-up visit and a haemodynamic diagnosis of pulmonary hypertension were enrolled in an 11-centre observational registry [14], initiated in October 2011. All patients were required to have at least one right heart catheterisation (RHC) demonstrating a mean pulmonary artery pressure (mPAP) $\geqslant 25 \mathrm{mmHg}$, in accordance with the 2015 European Society of Cardiology/ERS guidelines definition [10]. Incident cases were defined as the diagnosis of pulmonary hypertension within 1 year of entry into the registry, whereas prevalent cases were historically diagnosed more than a year prior. All information was recorded in a secure web-based electronic database (REDCap) [16]. Local institutional review board approval was obtained prior to entering any patient into the database. The authors used the STROBE (Strengthening the Reporting of Observational Studies in Epidemiology) checklist in preparing this report [17].

For each incident patient, the first RHC identifying pulmonary hypertension was used for diagnosis and to calculate transplant-free survival. For prevalent patients, survival time was calculated as time from registry entry. For example, a prevalent patient diagnosed 1 year prior to registry entry and followed for 5 years from diagnosis had survival time left-truncated at year 1 and right-censored at year 4 (48 months). RHC values recorded included the mean right atrial pressure (RAP), mPAP and systolic (sPAP) and diastolic (dPAP) pulmonary artery pressures, as well as the pulmonary capillary wedge pressure (PCWP) and thermodilution cardiac output. Pre-capillary SAPH was defined as an mPAP $\geqslant 25 \mathrm{mmHg}$ with a PCWP of $\leqslant 15 \mathrm{mmHg}$ [10]. Calculated pulmonary vascular resistance (cPVR) was calculated as mPAP - PCWP/ cardiac output.

Demographics collected included age, sex, race and duration of sarcoidosis. When available, the most recent chest radiograph at the time of entry into the study was reviewed and staged [18] by the enrolling investigator. Scadding staging was not centrally adjudicated. Physiological studies recorded included forced vital capacity $(\mathrm{FVC})$, forced expiratory volume in $1 \mathrm{~s}\left(\mathrm{FEV}_{1}\right), \mathrm{FEV}_{1} / \mathrm{FVC}$ ratio, single-breath diffusing capacity of the lung for carbon monoxide $\left(D_{\mathrm{LCO}}\right)$ and 6-min walk distance (6MWD) $[15,19,20]$.

Affiliations: ${ }^{1}$ INOVA Fairfax Hospital, Falls Church, VA, USA. ${ }^{2}$ Royal Brompton Hospital, London, UK. ${ }^{3}$ King Saud University, Riyadh, Saudi Arabia. ${ }^{4}$ Cleveland Clinic, Cleveland, $\mathrm{OH}$, USA. ${ }^{5}$ University of Alabama, Birmingham, AL, USA. ${ }^{6}$ Temple University, Philadelphia, PA, USA. ${ }^{7}$ Mayo Clinic, Rochester, MN, USA. ${ }^{8}$ University of Utah, Salt Lake City, UT, USA. ${ }^{9}$ Erasmus University Medical Centre, Rotterdam, The Netherlands. ${ }^{10}$ University of Southern California, Los Angeles, CA, USA. ${ }^{11}$ University of Cincinnati Medical Center, Cincinnati, OH, USA. ${ }^{12}$ The Christ Hospital, Cincinnati, OH, USA.

Correspondence: Oksana A. Shlobin, Pulmonary Hypertension Program, Inova Fairfax Hospital, 3300 Gallows Road, Falls Church VA 22042, USA. E-mail: oksana.shlobinđinova.org 
Investigators were asked to record historical and current use of pulmonary hypertension therapy, but no direction was given regarding choice of treatment. Duration of therapy was not captured. Demographics of patients on and off pulmonary arterial hypertension $(\mathrm{PAH})$ therapy were compared. Predefined cut-points of $6 \mathrm{MWD}, D_{\mathrm{LCO}}, \mathrm{mPAP}$ and cPVR were examined for their association with transplant-free survival [21-23].

The participating clinical centres were University of Cincinnati Medical Center (Cincinnati, OH, USA), Cleveland Clinic (Cleveland, OH), Inova Fairfax Hospital (Falls Church, VA, USA), University of Alabama (Birmingham, AL, USA), Temple University (Philadelphia, PA, USA), University of Southern California (Los Angeles, CA, USA), University of Utah (Salt Lake City, UT, USA), Mayo Clinic (Rochester, MN, USA), Erasmus University Medical Centre (Rotterdam, the Netherlands), The Christ Hospital (Cincinnati, $\mathrm{OH})$, the Royal Brompton Hospital (London, UK) and King Saud University (Riyadh, Saudi Arabia).

\section{Statistical analysis}

Statistical analysis was performed using STATA 11.0 (Stata Corp., College Station, TX, USA), and SAS (version 9.4; Cary, NC, USA). Data are presented as mean \pm SD or $\mathrm{n}(\%)$, where appropriate. Between-group differences were compared using t-test, Chi-squared test, Fisher's exact test or the Mann-WhitneyWilcoxon rank-sum test, as appropriate. Time to survival was calculated from the date of the first identifying RHC for incident patients and the date of SAPH diagnosis for prevalent patients. The KaplanMeier method was used to estimate the cumulative probability of outcomes, and between-group differences were compared using the log-rank test. Univariate Cox proportional hazard models were used to assess association between baseline covariates and all-cause mortality (presented as hazard ratio (HR) and 95\% confidence intervals). Univariate parameters were considered for inclusion in multivariate models with $\mathrm{p}<0.10$. For final multivariate models, $\mathrm{p}<0.05$ was considered statistically significant. For expected collinear terms (i.e. sPAP, dPAP, mPAP), those with the lowest p-value were deemed most statistically significant and included in multivariate models. Kaplan-Meier analysis was used to assess differences in cumulative survival. Transplanted patients were considered right-censored at the time of transplant. All statistical tests involving group comparisons were two-tailed, with p-values $<0.05$ considered statistically significant.

\section{Results}

Description of baseline data for the precapillary cohort

There were 215 patients enrolled over a 6-year period (last date of entry September 12, 2017) (figure 1). The majority of patients (159 (73.9\%) out of 215 ) had precapillary pulmonary hypertension, with $60 \%$ of patients enrolled from the USA, 24\% from Western Europe and 16\% from Saudi Arabia. A list of participating centres is included in the materials and methods section. The mean age of the overall precapillary cohort (referred to as the "precapillary cohort" from here on) was $56.9 \pm 10.6$ years with $72.3 \%$ female, 56\% African American and 31.4\% Caucasian and a mean duration between the time of initial

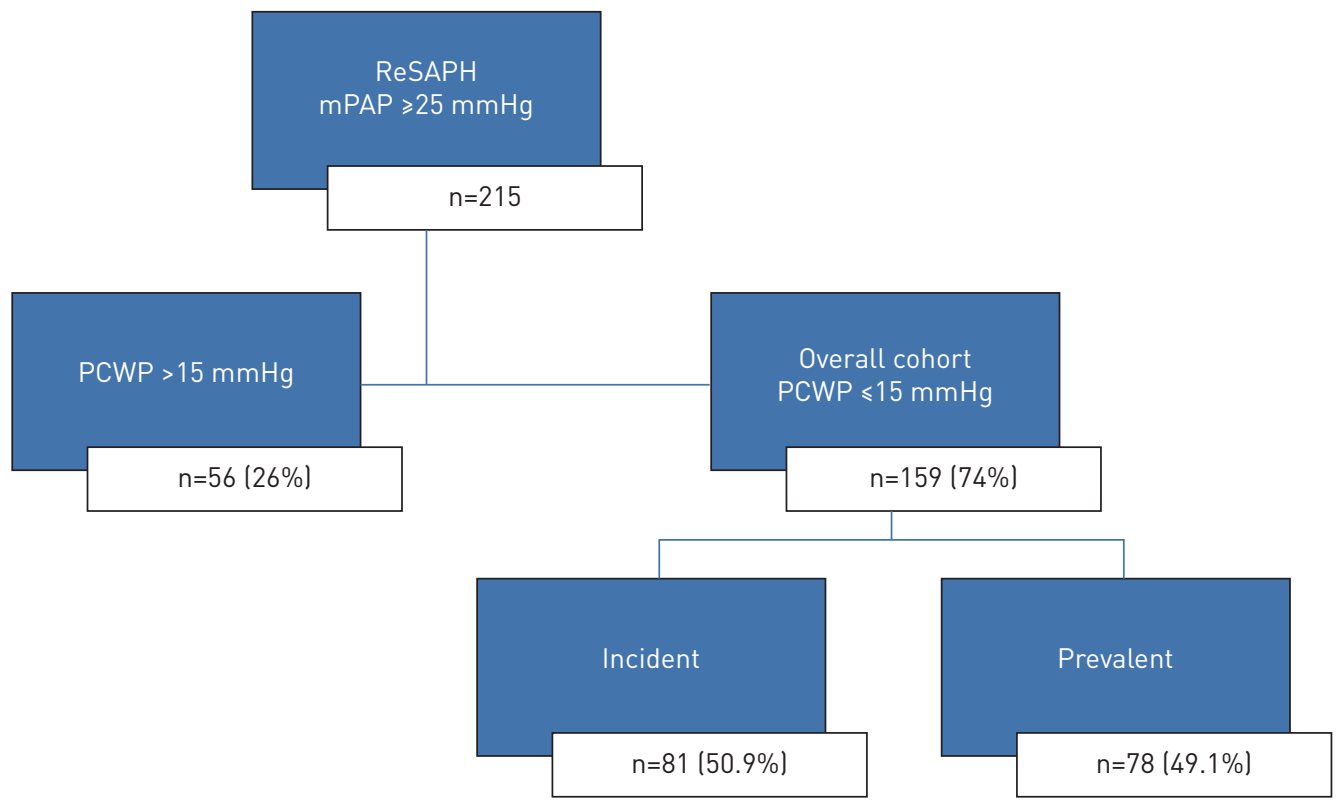

FIGURE 1 Registry for Sarcoidosis-Associated Pulmonary Hypertension (ReSAPH) flowchart. mPAP: mean pulmonary artery pressure; PCWP: pulmonary capillary wedge pressure. 


\begin{tabular}{|c|c|c|c|c|}
\hline & $\begin{array}{c}\text { Precapillary } \\
\text { SAPH }\end{array}$ & $\begin{array}{l}\text { Incident } \\
\text { SAPH }\end{array}$ & $\begin{array}{l}\text { Prevalent } \\
\text { SAPH }\end{array}$ & p-value ${ }^{\#}$ \\
\hline Subjects & 159 & $81(50.9)$ & $78(49.1)$ & \\
\hline Age years & $56.9 \pm 10.6$ & $57.0 \pm 11.2$ & $56.7 \pm 10.0$ & 0.862 \\
\hline \multicolumn{5}{|l|}{ Sex } \\
\hline Female & 115 (72.3) & 61 (75.3) & $54(69.2)$ & \\
\hline Male & $44(27.7)$ & $20(24.7)$ & $24(30.8)$ & 0.392 \\
\hline \multicolumn{5}{|l|}{ Race } \\
\hline Caucasian & $50(31.4)$ & $24(29.6)$ & 26 (33.3) & \\
\hline African/American & $89(56.0)$ & $38(46.9)$ & $51(65.4)$ & \\
\hline Other & 20 (12.5) & $19(23.4)$ & $1(1.3)$ & 0.001 \\
\hline $\begin{array}{l}\text { Time between initial sarcoidosis diagnosis } \\
\text { and SAPH years }\end{array}$ & $14.1 \pm 10.9$ & $12.9 \pm 12.0$ & $15.3 \pm 9.7$ & 0.167 \\
\hline Baseline oxygen saturation $\%$ & $93.6 \pm 4.5$ & $93.5 \pm 4.5$ & $94.7 \pm 4.3$ & 0.152 \\
\hline FVC L & $2.04 \pm 0.76$ & $2.0 \pm 0.8$ & $2.1 \pm 0.8$ & 0.495 \\
\hline FVC \% pred & $62.4 \pm 19.7$ & $60.4 \pm 18.5$ & $64.3 \pm 20.9$ & 0.225 \\
\hline $\mathrm{FEV}_{1} \mathrm{~L}$ & $1.4 \pm 0.6$ & $1.4 \pm 0.5$ & $1.3 \pm 0.5$ & 0.340 \\
\hline FEV $_{1} \%$ pred & $55.2 \pm 19.9$ & $57.0 \pm 18.6$ & $53.4 \pm 21.2$ & 0.266 \\
\hline $\mathrm{FEV}_{1} / \mathrm{FVC}$ ratio & $70.9 \pm 16.7$ & $75.2 \pm 16.1$ & $66.6 \pm 16.2$ & 0.001 \\
\hline$D_{\text {Lco }} \mathrm{mL} \cdot \mathrm{min}^{-1} \cdot \mathrm{mmHg}^{-1}$ & $9.3 \pm 10.1$ & $12.1 \pm 13.3$ & $6.8 \pm 4.6$ & 0.003 \\
\hline$D_{\text {Lco }} \%$ pred & $40.0 \pm 15.9$ & $41.7 \pm 15.5$ & $38.4 \pm 16.1$ & 0.263 \\
\hline 6MWD m & $302.6 \pm 119.3$ & $296.2 \pm 127.3$ & $311.8 \pm 108.4$ & 0.469 \\
\hline RAP mmHg & $6.4 \pm 4.6$ & $6.4 \pm 5.0$ & $6.4 \pm 4.1$ & 0.967 \\
\hline SPAP $\mathrm{mmHg}$ & $58.15 \pm 14.9$ & $56.2 \pm 14.1$ & $60.2 \pm 15.7$ & 0.094 \\
\hline dPAP mmHg & $23.4 \pm 8.0$ & $22.7 \pm 8.5$ & $24.2 \pm 7.5$ & 0.244 \\
\hline mPAP mmHg & $36.9 \pm 9.2$ & $35.8 \pm 8.9$ & $38.1 \pm 9.6$ & 0.118 \\
\hline PCWP mmHg & $9.3 \pm 3.2$ & $9.3 \pm 3.1$ & $9.3 \pm 3.4$ & 0.952 \\
\hline cPVR Woods units & $5.9 \pm 3.4$ & $5.4 \pm 3.0$ & $6.3 \pm 3.7$ & 0.101 \\
\hline Cardiac output L. $\min ^{-1}$ & $5.4 \pm 1.7$ & $5.4 \pm 1.5$ & $5.4 \pm 1.9$ & 0.894 \\
\hline SAPH therapy & $115(72.3)$ & 48 (59.3) & $67(86.0)$ & 0.003 \\
\hline Sarcoid therapy & $122(76.7)$ & $58(71.6)$ & $64(82.1)$ & 0.512 \\
\hline Prednisone daily dose $\mathrm{mg}$ & $12.7 \pm 9.9$ & $15.8 \pm 11.4$ & $10.1 \pm 7.4$ & 0.002 \\
\hline Survival & $117(74.1)$ & $56(70.0)$ & $61(78.2)$ & 0.195 \\
\hline Follow-up years & $2.4 \pm 1.9$ & $2.4 \pm 1.8$ & $2.4 \pm 1.6$ & 0.999 \\
\hline
\end{tabular}

Data are presented as $n, n(\%)$ or mean \pm SD, unless otherwise stated. Bold type represents statistical significance. SAPH: sarcoidosis-associated pulmonary hypertension; FVC: forced vital capacity; $\mathrm{FEV}_{1}$ : forced expiratory volume in $1 \mathrm{~s} ; D_{\mathrm{LCO}}$ : diffusing capacity of the lung for carbon monoxide; 6MWD: 6-min walk distance; RAP: right atrial pressure; SPAP: systolic pulmonary artery pressure; dPAP: diastolic pulmonary artery pressure; mPAP: mean pulmonary artery pressure; PCWP: pulmonary capillary wedge pressure; cPVR: calculated pulmonary vascular resistance. "\#: statistical comparisons compare incident and prevalent precapillary SAPH groups.

\begin{tabular}{|c|c|}
\hline \multicolumn{2}{|c|}{ Pulmonary function tests } \\
\hline FVC \% pred & $62.4 \pm 19.7$ \\
\hline $\mathrm{FEV}_{1} \%$ pred & $55.2 \pm 19.9$ \\
\hline $\mathrm{FEV}_{1} / \mathrm{FVC}_{0} \%$ pred & $70.9 \pm 16.7$ \\
\hline$D_{\text {Lco }} \%$ pred & $40.0 \pm 15.9$ \\
\hline \multicolumn{2}{|c|}{ Radiography Scadding staging } \\
\hline Subjects & 125 \\
\hline 1 & $3(2.4)$ \\
\hline$\|-\| \|$ & $31(24.8)$ \\
\hline IV & $82(65.6)$ \\
\hline 6MWD m & $302.6 \pm 119.3$ \\
\hline
\end{tabular}

Data are presented as mean $\pm S D, n$ or $n(\%)$. FVC: forced vital capacity; FEV $_{1}$ : forced expiratory volume in $1 \mathrm{~s} ; D_{\mathrm{LCO}}$ : diffusing capacity of the lung for carbon monoxide. 

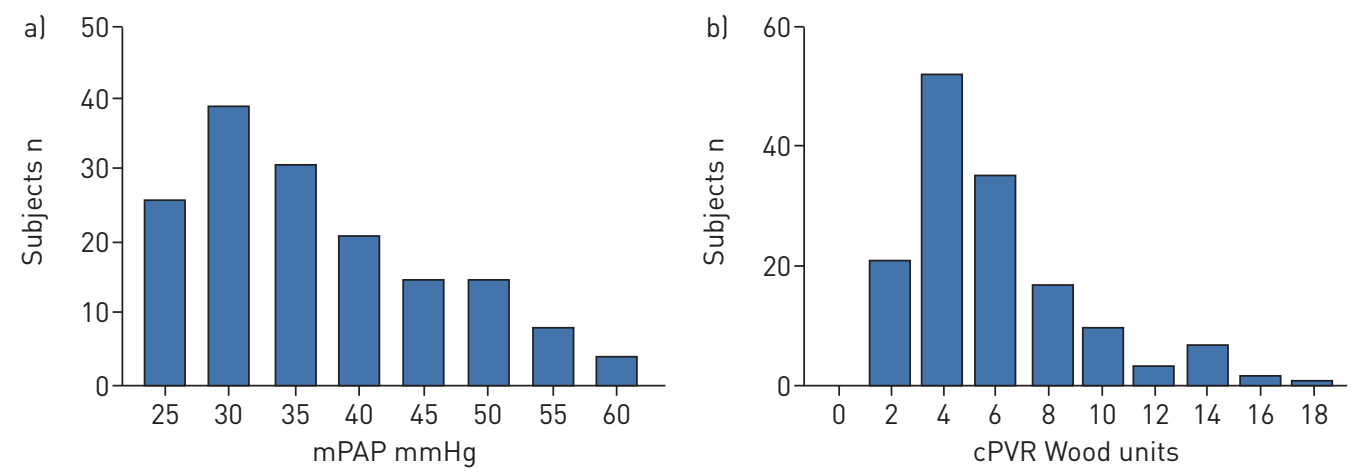

FIGURE 2 Distribution of a) mean pulmonary artery pressure (mPAP) and b) calculated pulmonary vascular resistance (cPVR) in the precapillary cohort.

sarcoidosis diagnosis and SAPH of $12.6 \pm 11.8$ years (table 1). 125 (78.6\%) patients had documentation of radiographic Scadding staging (table 2).

A comprehensive haemodynamic profile was available in 148 (93.1\%) of the patients (no cardiac output documented in 11 patients) (table 1). The mean mPAP of the cohort was $36.9 \pm 9.2 \mathrm{mmHg}$ (figure $2 \mathrm{a}$ ), mean PCWP 9.3 $\pm 3.2 \mathrm{mmHg}$ and mean cardiac output $5.4 \pm 1.7 \mathrm{~L} \cdot \mathrm{min}^{-1}$. The mean cPVR was $5.9 \pm 3.4$ Wood units (WU) (figure $2 \mathrm{~b}$ ), while the mean TPR was $7.8 \pm 3.9 \mathrm{WU}$.

The mean FVC of the group was $62.4 \pm 19.7 \%$ predicted with a mean $D_{\text {LCO }} 40.0 \pm 15.9 \%$ pred. Airflow obstruction $\left(\mathrm{FEV}_{1} / \mathrm{FVC}<70 \%\right)$ was identified in $58(36.5 \%)$ out of 159 patients (table 1$)$. Patients were limited functionally, with a mean 6MWD of $302.6 \pm 119.3 \mathrm{~m}$ (table 2), with no correlation between the $\mathrm{mPAP}$ and 6MWD ( $\mathrm{r}=-0.11, \mathrm{p}<0.187)$ (figure 3$) .122(76.7 \%)$ of patients were on sarcoidosis-specific treatment at the time of study entry, whereas PAH-specific treatment was reported in $115(72.3 \%)$ of patients (table 3).

\section{Comparison of incident versus prevalent precapillary subgroups at baseline}

Demographics were similar between the incident $(n=81,50.9 \%)$ and prevalent groups $(n=78,49.1 \%)$, except for race, with a higher percentage of African Americans in the latter group (65.4\% versus $46.9 \%$ ) (table 1). In the prevalent group, the average time from SAPH diagnosis to entry into the registry was $60.4 \pm 46.5$ months and the average time from most recent RHC and enrolment into the registry was $15.2 \pm 9.7$ months. In the incident group, the average time from SAPH diagnosis to registry enrolment was $3.7 \pm 6.1$ months. Pulmonary function tests demonstrated similar restriction; however, the incident cohort demonstrated less obstruction by $\mathrm{FEV}_{1} / \mathrm{FVC}$ ratio $(75.2 \pm 16.1$ versus $66.6 \pm 16.2, \mathrm{p}=0.001)$, and a higher mean $D_{\mathrm{LCO}}\left(12.1 \pm 13.3 \mathrm{mmol} \cdot \mathrm{min}^{-1} \cdot \mathrm{mmHg}^{-1}\right.$ versus $\left.6.8 \pm 4.6 \mathrm{mmol} \cdot \mathrm{min}^{-1} \cdot \mathrm{mmHg}^{-1}, \mathrm{p}=0.003\right)$. The severity of pulmonary hypertension was similar between groups, although the sPAP was slightly higher numerically in the prevalent cohort $(56.2 \pm 14.1 \mathrm{mmHg}$ versus $60.2 \pm 15.7$ $\mathrm{mmHg}, \mathrm{p}=0.0939$ ). The prevalent group was much more likely to be treated with PAH-specific therapy and receive a lower dose of prednisone.

FIGURE 3 Mean pulmonary artery pressure (mPAP) versus 6-min walk distance (6MWD) in the precapillary cohort.

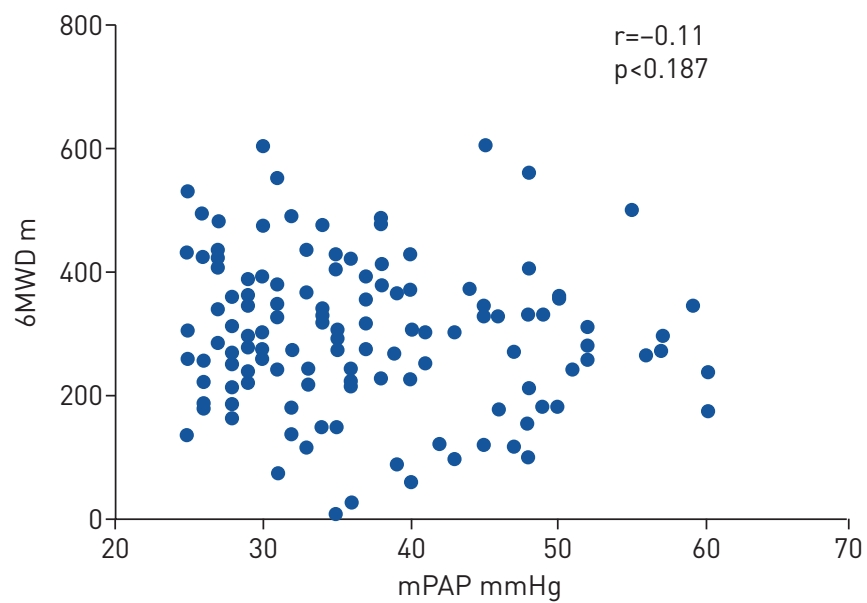




$\begin{array}{lr}\text { TABLE } 3 \text { Pulmonary artery hypertension-specific agent use }{ }^{\#} \text { in the precapillary cohort } \\ \text { PDE-5i } & 86(53.4) \\ \text { Sildenafil } & 66(76.7) \\ \text { Tadalafil } & 20(23.3) \\ \text { ERA } & 56(34.8) \\ \text { Ambrisentan } & 18(32.1) \\ \text { Bosentan } & 38(67.9) \\ \text { PDE-5i + ERA combination } & 28(17.6) \\ \text { PDE-5i + ERA + prostanoid combination } & 10(6.3)\end{array}$

Data are presented as n (\%). PDE-5i: phosphodiesterase-5 inhibitor; ERA: endothelin antagonist. " : current or historical use.

Transplant-free survival analysis of the precapillary cohort

41 (25.8\%) patients died and nine (5.7\%) were transplanted. Overall, the Kaplan-Meier-adjusted 1-, 3- and 5-year transplant-free survival was $89.2 \%, 71.7 \%$ and $62.0 \%$, respectively. In the incident subgroup, the Kaplan-Meier-adjusted 1-, 3- and 5-year transplant-free survival was $83.5 \%, 70.3 \%$ and $58.3 \%$. In the prevalent subgroup, the Kaplan-Meier-adjusted 1-, 3- and 5-year transplant-free survival was 94.7\%, $72.2 \%$ and $66.3 \%$, respectively. There was no difference in transplant-free survival between the two subgroups $(\mathrm{p}<0.202)$ (figure 4$)$.

In the precapillary cohort, transplant-free survival was not associated with any demographic characteristics, including age, sex or race. Nor was the presence of parenchymal nor fibrocystic disease on chest radiography associated with outcomes. Severe pulmonary hypertension (defined as mPAP $\geqslant 35 \mathrm{mmHg}$ ) and median cPVR $\geqslant 4.4 \mathrm{WU}$ were not predictors of worse outcome. However, severe gas transfer impairment $\left(D_{\mathrm{LCO}}<35 \%\right.$ pred) and $6 \mathrm{MWD}<300 \mathrm{~m}$ were strong predictors of decreased transplant-free survival ( $\mathrm{p}=0.015$ and $\mathrm{p}<0.001$, respectively) (figure 5). In the prevalent cohort, 6MWD $<300 \mathrm{~m}$ was found to be a predictor of decreased transplant-free survival $(\mathrm{p}<0.009)$ (figure $6 \mathrm{a})$. In the incident cohort, both severe gas transfer impairment and $6 \mathrm{MWD}<300 \mathrm{~m}$ were strong predictors of decreased transplant-free survival ( $\mathrm{p}<0.037$ and $\mathrm{p}<0.002$, respectively) (figure $6 \mathrm{~b}$ ). When the most recent definition of pulmonary hypertension [11] was applied to the cohort, exclusion of 20 patients with cPVR $<3 \mathrm{WU}$ did not change the above associations (graphs not provided). The use of PAH-specific medication at time of enrolment in the study was not associated with improvement in transplant-free survival; however, patients receiving PAH-specific agents appeared to be have more severe SAPH, with lower $D_{\text {LCO }}$ percentages and higher RAP, sPAP, mPAP and cPVR (table 4).

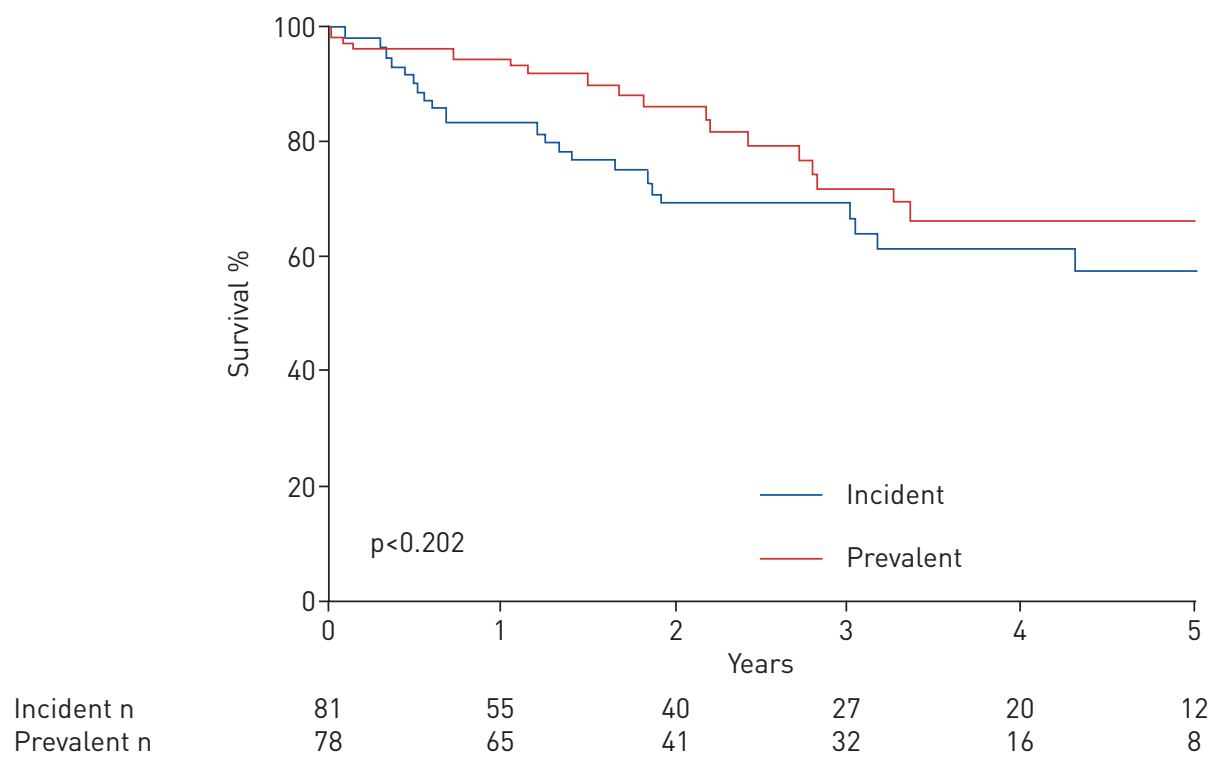

FIGURE 4 Kaplan-Meier transplant-free survival curves for incident and prevalent subgroups. 



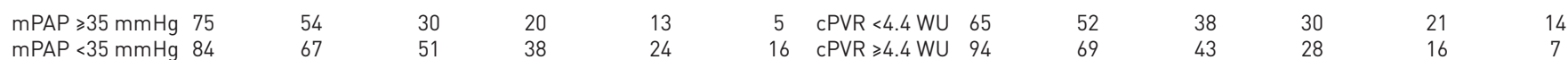

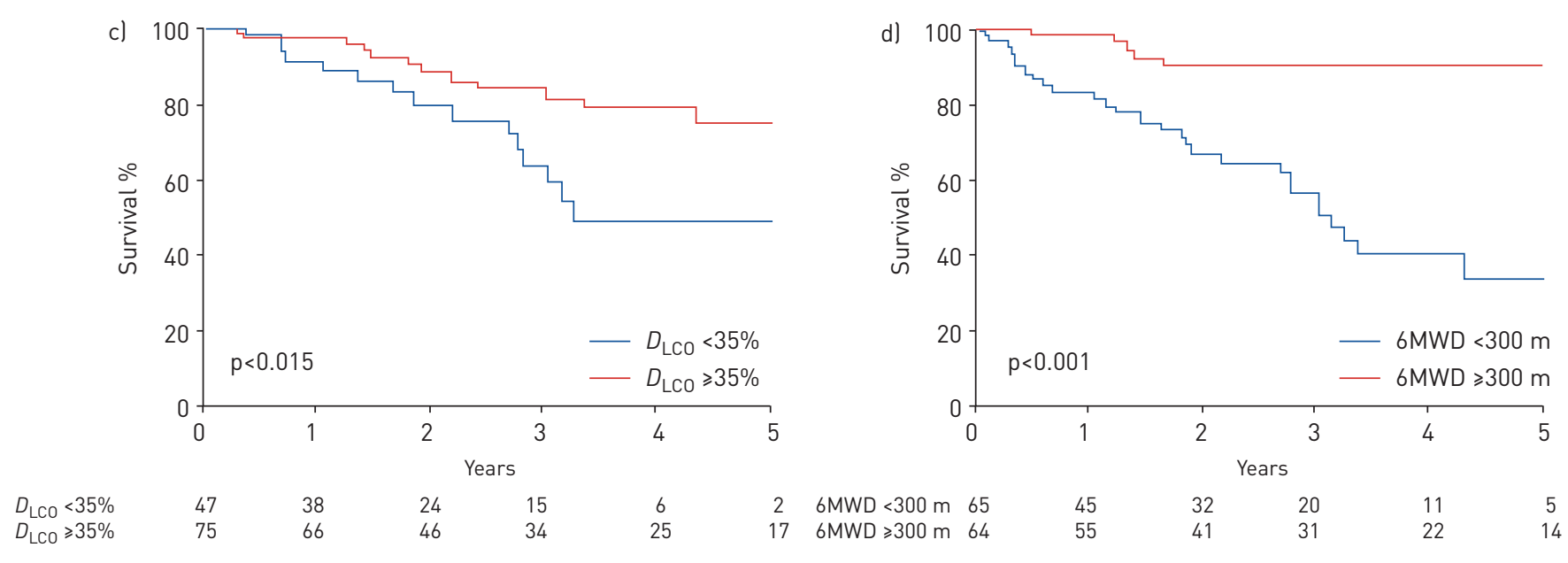

FIGURE 5 Kaplan-Meier transplant-free survival curves for relationship with a) mean pulmonary artery pressure (mPAP) $\geqslant 35$ mmHg, b) calculated pulmonary vascular resistance (cPVR) $\geqslant 4.4$ Wood units (WU), c) diffusing capacity of the lung for carbon monoxide $\left(D_{\text {Lco }}\right)$ threshold of $35 \%$ predicted and d) 6 -min walk distance (6MWD) threshold of $300 \mathrm{~m}$ in the precapillary cohort.

\section{Univariate predictors of transplant-free survival in the precapillary cohort}

Transplant-free survival was strongly associated with a higher 6MWD (HR 0.95, 95\% CI 0.92-0.97; p=0.001), age (HR 1.05, 95\% CI 1.05-1.08; $\mathrm{p}=0.009$ ) and $D_{\text {LCO }}$ (HR 0.97, 95\% CI 0.94-0.99; p=0.012) (table 5). The only haemodynamic parameter that trended towards statistical significance with transplant-free survival by univariate analysis was sPAP (HR 1.02, 95\% CI 1.00-1.04; $\mathrm{p}=0.051$ ) and a lower $\mathrm{FEV}_{1} / \mathrm{FVC}$ ratio (HR 1.02, 95\% CI 1.00-1.05; $\mathrm{p}=0.061$ ). Data for incident and prevalent groups are presented in table 5.

Multivariate predictors of transplant-free survival in the precapillary cohort

A final multivariate Cox proportional hazards model was created with the independent predictors of outcomes from each domain described herein. Statistically significant parameters with univariate hazard ratios whose $\mathrm{p}$-values were $<0.10$ were considered for inclusion in the model. For expected collinear terms, such as haemodynamic parameters, variables with the lowest p-value were included in the final model. In the final multivariate model, the $\mathrm{FEV}_{1} / \mathrm{FVC}$ (HR 1.05, 95\% CI 1.06-1.10; $\mathrm{p}=0.019$ ) and 6MWD (HR 0.94, 95\% CI 0.89-0.99; $\mathrm{p}=0.003$ ) remained independent predictors of outcomes (table 6).

\section{Subgroup analyses}

Univariate and multivariate analyses of prevalent/incident subgroups of the overall cohort are shown in tables 5 and 6 . In univariate analysis, the $D_{\mathrm{LCO}}, 6 \mathrm{MWD}$ and $\mathrm{SPAP}$ in the incident group and 6MWD in the prevalent group (table 5) were statistically significant predictors of transplant-free survival. None of the variables reached statistical significance as predictors of outcomes in either subgroup (table 5) in the multivariate analysis, although in the prevalent cohort, 6MWD was nearly statistically significant $(\mathrm{p}<0.055)$. 


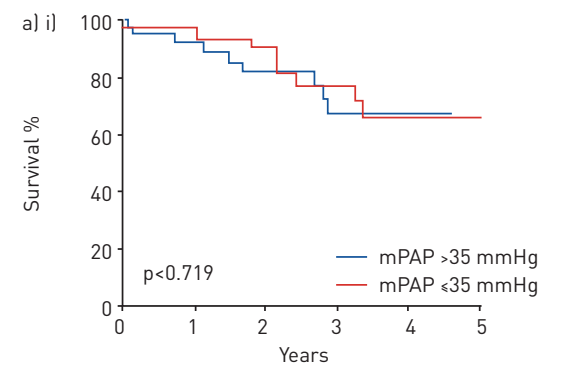

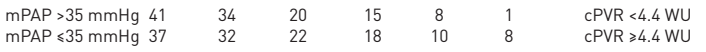

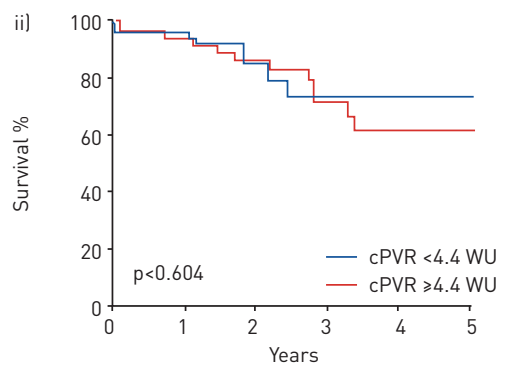





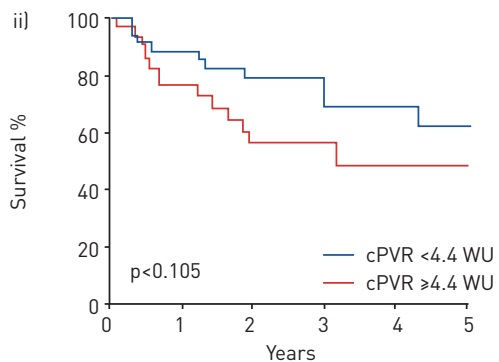

$\begin{array}{llllccc}\text { CPVR }<4.4 \text { WU } & 39 & 31 & 24 & 18 & 13 & 8 \\ \operatorname{cPVR} \geqslant 4.4 \mathrm{WU} & 36 & 22 & 14 & 9 & 6 & 3\end{array}$

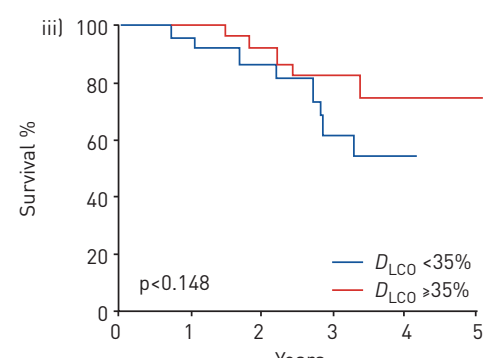

$\begin{array}{ll}D_{\mathrm{LCO}}<35 \% & 2 \\ D_{\mathrm{LCO}} \geqslant 35 \% & 36\end{array}$

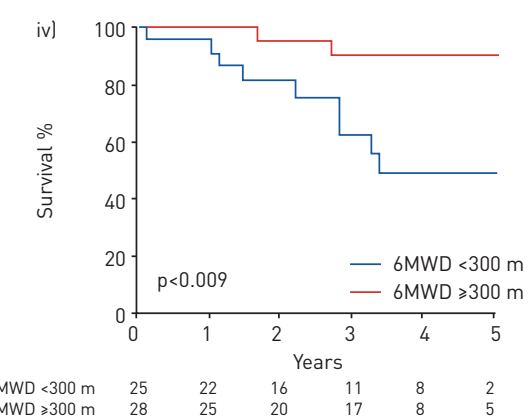



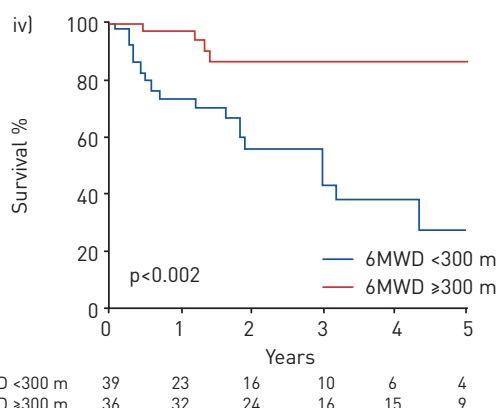

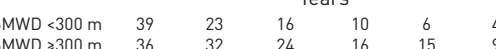

FIGURE 6 Kaplan-Meier transplant-free survival curves for relationship with i) mean pulmonary artery pressure (mPAP) $\geqslant 35 \mathrm{mmHg}$, ii) calculated pulmonary vascular resistance (cPVR) $\geqslant 4.4$ Wood units (WU), iii) diffusing capacity of the lung for carbon monoxide $\left(D_{\mathrm{Lco}}\right) 35 \%$ predicted and iv) 6 -min walk distance (6MWD) threshold of $300 \mathrm{~m}$ in a) the prevalent subgroup of the precapillary cohort and b) the incident subgroup of the precapillary cohort. 
TABLE 4 Comparison of demographics for the precapillary cohort on and off pulmonary artery hypertension (PAH)-specific therapy

\begin{tabular}{|c|c|c|c|}
\hline & $\begin{array}{l}\text { No PAH } \\
\text { therapy }\end{array}$ & $\begin{array}{l}\text { PAH } \\
\text { therapy }\end{array}$ & p-value \\
\hline Subjects & $44(27.7)$ & 115 (72.3) & \\
\hline Age years & $58.7 \pm 9.7$ & $57.1 \pm 9.7$ & 0.325 \\
\hline Oxygen saturation index & $94.5 \pm 3.5$ & $93.8 \pm 4.8$ & 0.432 \\
\hline FVC L & $2.0 \pm 0.8$ & $2.0 \pm 0.8$ & 0.981 \\
\hline FVC $\%$ predicted & $59.9 \pm 19.8$ & $62.9 \pm 20.0$ & 0.454 \\
\hline $\mathrm{FEV}_{1} \mathrm{~L}$ & $1.3 \pm 0.6$ & $1.4 \pm 0.5$ & 0.660 \\
\hline $\mathrm{FEV}_{1} \%$ predicted & $53.0 \pm 21,1$ & $55.3 \pm 19.7$ & 0.546 \\
\hline $\mathrm{FEV}_{1} / \mathrm{FVC}$ & $67.7 \pm 17.5$ & $71.2 \pm 16.6$ & 0.303 \\
\hline$D_{\text {Lco }} \mathrm{mmol} \cdot \mathrm{min}^{-1} \cdot \mathrm{mmHg}^{-1}$ & $14.6 \pm 19.2$ & $7.9 \pm 5.5$ & 0.003 \\
\hline$D_{\text {Lco }} \%$ predicted & $43.7 \pm 18.1$ & $38.8 \pm 15.1$ & 0.207 \\
\hline 6MWD m & $305.2 \pm 137.8$ & $296.2 \pm 111.5$ & 0.790 \\
\hline RAP mmHg & $4.9 \pm 2.4$ & $6.6 \pm 4.7$ & 0.008 \\
\hline sPAP $\mathrm{mmHg}$ & $51.8 \pm 11.9$ & $60.0 \pm 15.1$ & 0.006 \\
\hline dPAP $\mathrm{mmHg}$ & $21.8 \pm 10.0$ & $23.9 \pm 7.3$ & 0.204 \\
\hline mPAP mmHg & $33.0 \pm 7.7$ & $38.0 \pm 9.2$ & 0.006 \\
\hline PCWP mmHg & $9.5 \pm 3.1$ & $9.2 \pm 3.3$ & 0.728 \\
\hline LVEDP $\mathrm{mmHg}$ & $14.8 \pm 1.3$ & $16.8 \pm 29.6$ & 0.889 \\
\hline Cardiac output & $5.7 \pm 1.3$ & $5.3 \pm 1.8$ & 0.185 \\
\hline cPVR Woods units & $4.5 \pm 2.2$ & $6.4 \pm 3.6$ & 0.005 \\
\hline $\begin{array}{l}\text { Time between diagnosis of sarcoid and pulmonary } \\
\text { hypertension years }\end{array}$ & $14.2 \pm 11.1$ & $10.3 \pm 10.6$ & 0.092 \\
\hline Prednisone daily dose & $15.8 \pm 13.5$ & $12.2 \pm 8.7$ & 0.110 \\
\hline Survival years & $5.0 \pm 4.4$ & $5.1 \pm 4.0$ & 0.891 \\
\hline \multicolumn{4}{|c|}{$\begin{array}{l}\text { Data are presented as } \mathrm{n}(\%) \text { or mean } \pm \mathrm{SD} \text {, unless otherwise stated. Bold type represents statistical significance. } \\
\text { FVC: forced vital capacity; FEV } 1 \text { : forced expiratory volume in } 1 \mathrm{~s} ; D_{\mathrm{LCO}} \text { : diffusing capacity of the lung for carbon } \\
\text { monoxide; } 6 \mathrm{MWD} \text { : } 6 \text {-min walk distance; RAP: right atrial pressure; SPAP: systolic pulmonary artery pressure; } \\
\text { dPAP: diastolic pulmonary artery pressure; mPAP: mean pulmonary artery pressure; PCWP: pulmonary } \\
\text { capillary wedge pressure; LVEDP: left ventricular end-diastolic pressure; cPVR: calculated pulmonary vascular } \\
\text { resistance. }\end{array}$} \\
\hline
\end{tabular}

\section{Discussion}

The prevalence and impact of SAPH have only been recently appreciated. Due to the relatively low incidence of $\mathrm{SAPH}$, prior reports have mostly emanated from single-centre retrospective studies $[3,5,6,9$, 11, 21-30]. To address this issue, we established a multicentre international observational registry to capture the demographics, treatment and outcomes of SAPH across a wide geographic and ethnically diverse population. Demographic characteristics of the first 178 SAPH patients have been reported previously [14]. The present article builds further on that publication and is the largest report to date describing outcomes of patients with SAPH.

Multiple studies have demonstrated that development of pulmonary hypertension is associated with higher mortality in patients with sarcoidosis $[1,3,5,11,25]$. In this report, the outcomes of the overall cohort were similar to those previously described [22, 31-33], with a 3-year transplant-free survival of $\sim 71 \%$. There was no association between mortality and any demographic parameters. Earlier studies have suggested that the presence of pulmonary hypertension was associated with a higher prevalence of stage 4 parenchymal disease [30]. In this registry, Scadding staging was assessed on chest radiographs without central adjudication. With subsequent inherent limitations, of the $79 \%$ of SAPH patients with imaging available for Scadding staging, $65.6 \%$ had stage 4 disease. Only $2 \%$ of patients had stage 1 disease, suggesting that the lack of lung opacities on imaging is a fairly sensitive test for the absence of SAPH.

Although a number of factors was associated with survival in univariate analysis, only the $\mathrm{FEV}_{1} / \mathrm{FVC}$ ratio and 6MWD withstood the scrutiny of a multivariate analysis to emerge as independently associated with outcomes in the analysed cohort. The demonstrated association of a lower $\mathrm{FEV}_{1} / \mathrm{FVC}$ with improved outcomes is the first such description. A previous study [30] demonstrated no correlation between obstructive spirometric physiology and SAPH. We speculate that SAPH patients with evidence of obstruction may represent a subset with predominantly airway involvement with possibly less likelihood for contiguous vascular disease, thus portending a better outcome. An alternative explanation may be the reduced lung compliance among patients with higher $\mathrm{FEV}_{1} / \mathrm{FVC}$ ratios. 
TABLE 5 Univariate hazard ratios $(95 \% \mathrm{CI})$ for survival in the precapillary cohort with incident and prevalent subgroups

\begin{tabular}{|c|c|c|c|c|c|c|}
\hline Parameter & Precapillary & p-value & Incident & p-value & Prevalent & p-value \\
\hline Subjects $\mathrm{n}$ & 159 & & 81 & & 78 & \\
\hline Age years & $1.04(1.01-1.08)$ & 0.023 & $1.03(0.99-1.07)$ & 0.131 & $1.06(0.98-1.14)$ & 0.137 \\
\hline Male & $1.48(0.78-2.80)$ & 0.227 & $1.77(0.76-4.15)$ & 0.188 & $1.67(0.62-4.31)$ & 0.319 \\
\hline \multicolumn{7}{|l|}{ Race } \\
\hline Caucasian & $0.93(0.31-2.85)$ & 0.014 & $1.40(0.42-4.68)$ & 0.580 & $1.33(0.49-3.61)$ & 0.582 \\
\hline African American & $0.68(0.23-2.02)$ & 0.490 & $0.75(0.29-1.93)$ & 0.522 & Ref. & Ref. \\
\hline Other & Ref. & Ref. & Ref. & Ref. & & \\
\hline FVC L, \% predicted & $0.99(0.97-1.01)$ & 0.222 & $0.99(0.96-1.01)$ & 0.264 & $0.99(0.97-1.03)$ & 0.729 \\
\hline $\mathrm{FEV}_{1} \mathrm{~L}, \%$ predicted & $1.00(0.98-1.01)$ & 0.957 & $0.99(0.97-1.01)$ & 0.238 & $1.01(0.98-1.03)$ & 0.640 \\
\hline $\mathrm{FEV}_{1} / \mathrm{FVC}$ ratio & $1.03(1.00-1.05)$ & 0.041 & $1.00(0.98-1.03)$ & 0.832 & $1.03(0.99-1.08)$ & 0.113 \\
\hline $\begin{array}{l}D_{\text {Lco }} \mathrm{mL} \cdot \mathrm{min}^{-1} \cdot \mathrm{mmHg}^{-1} \text {, } \\
\% \text { predicted }\end{array}$ & $0.98(0.95-1.00)$ & 0.060 & $0.96(0.92-1.00)$ & 0.035 & $0.98(0.94-1.02)$ & 0.236 \\
\hline 6MWD m, per $10 \mathrm{~m}$ & $0.95(0.92-0.97)$ & 0.003 & $0.95(0.92-0.98)$ & 0.004 & $0.92(0.88-0.97)$ & 0.002 \\
\hline RAP $\mathrm{mmHg}$ & $0.96(0.88-1.04)$ & 0.313 & $0.94(0.84-1.05)$ & 0.292 & $0.99(0.86-1.13)$ & 0.861 \\
\hline sPAP mmHg & $1.01(0.99-1.03)$ & 0.178 & $1.03(1.01-1.06)$ & 0.010 & $1.01(0.98-1.04)$ & 0.663 \\
\hline dPAP $\mathrm{mmHg}$ & $1.01(0.97-1.04)$ & 0.625 & 1.01 (0.97-1.05) & 0.602 & $1.02(0.97-1.08)$ & 0.480 \\
\hline mPAP $\mathrm{mmHg}$ & $1.01(0.98-1.04)$ & 0.408 & $1.04(1.00-1.08)$ & 0.073 & $1.01(0.97-1.06)$ & 0.655 \\
\hline PCWP mmHg & $1.03(0.94-1.14)$ & 0.546 & $1.04(0.91-1.19)$ & 0.603 & $1.03(0.89-1.20)$ & 0.669 \\
\hline cPVR & $1.02(0.93-1.11)$ & 0.706 & $1.09(0.97-1.22)$ & 0.130 & $1.00(0.88-1.15)$ & 0.954 \\
\hline Cardiac output & $0.91(0.75-1.10)$ & 0.319 & $0.86(0.64-1.15)$ & 0.306 & $0.93(0.70-1.25)$ & 0.643 \\
\hline PAH therapy & $1.37(0.59-3.19)$ & 0.465 & $2.01(0.74-5.45)$ & 0.170 & $2.55(0.52-12.32)$ & 0.243 \\
\hline Sarcoid therapy & $0.71(0.31-1.63)$ & 0.422 & $0.59(0.22-1.57)$ & 0.289 & $0.99(0.22-4.46)$ & 0.994 \\
\hline Prednisone daily dose mg & $1.02(0.99-1.06)$ & 0.244 & $1.03(0.98-1.07)$ & 0.283 & $0.98(0.91-1.05)$ & 0.558 \\
\hline
\end{tabular}

Bold type represents statistical significance. Statistically significant univariate hazard ratios were considered for the inclusion in multivariate models with $p<0.10$. FVC: forced vital capacity; $F E V_{1}$ : forced expiratory volume at $1 \mathrm{~s} ; D_{\mathrm{Lco}}$ : diffusing capacity of the lung for carbon monoxide; 6MWD: 6-min walk distance; RAP: right atrial pressure; SPAP: systolic pulmonary artery pressure; dPAP: diastolic pulmonary artery pressure; mPAP: mean pulmonary artery pressure; PCWP: pulmonary capillary wedge pressure; cPVR: calculated pulmonary vascular resistance; PAH: pulmonary arterial hypertension.

There are no published guidelines for treating SAPH. The limited supportive evidence for treating SAPH emanates mostly from single-centre and/or retrospective studies [27, 33-39]. As previously noted in this cohort, US-based centres are less likely to use PAH therapies than non-US centres [14]. The majority of patients $(\sim 72 \%)$ were on therapy, similar to a recent French registry where nearly all subjects were treated with off-label medications [6]. The use of PAH-specific therapies at the time of enrolment into the study did not appear to be associated with improved transplant-free survival in this study. However, the length of treatment was not recorded, which may have impacted the results. In addition, treated patients appeared to have more severe SAPH at baseline, possibly implying that the outcomes would be worse without treatment. It is plausible that providers may feel more justified to treat more severe SAPH patients with off-label PAH therapies, thus reflecting an apparent "standard of care" that has evolved based on expert opinion with only one placebo-controlled trial [39].

In the previously published French registry, which enrolled patients with severely affected haemodynamics, 3 - and 5-year survival were $74 \%$ and $55 \%$, respectively [8]. These findings are quite similar to ours, despite our population representing a more diverse cohort, which includes both incident and prevalent subgroups. As expected, patients in the prevalent cohort had longer transplant-free survival. The explanation for this is probably two-fold: survival bias in the prevalent cohort due to enrichment with less severe cases and lead-time bias as the prevalent subgroup was further along the disease course. The goal of the registry was to capture as many patients with this rare complication of sarcoidosis as possible; therefore, the authors felt the study design was justified.

In PAH, it is typically the variables that reflect right ventricular failure, such as the cardiac index and right atrial pressures, that correlate most closely with outcomes [39]. The ReSAPH cohort had relatively preserved haemodynamics that reflect well-preserved right ventricular function, with only $19 \%$ of our patients having right atrial pressures $>10 \mathrm{mmHg}$, while only $28 \%$ had cardiac indices $<2.5 \mathrm{~L} \cdot \mathrm{min}^{-1} \cdot \mathrm{m}^{-2}$. In the present analysis, severity of pulmonary hypertension, as measured by mPAP and PVR, was not demonstrated to be associated with worse outcomes. As the registry recruits more patients, we plan to re-analyse the data. A possible explanation for this apparent lack of association might be severity bias; 


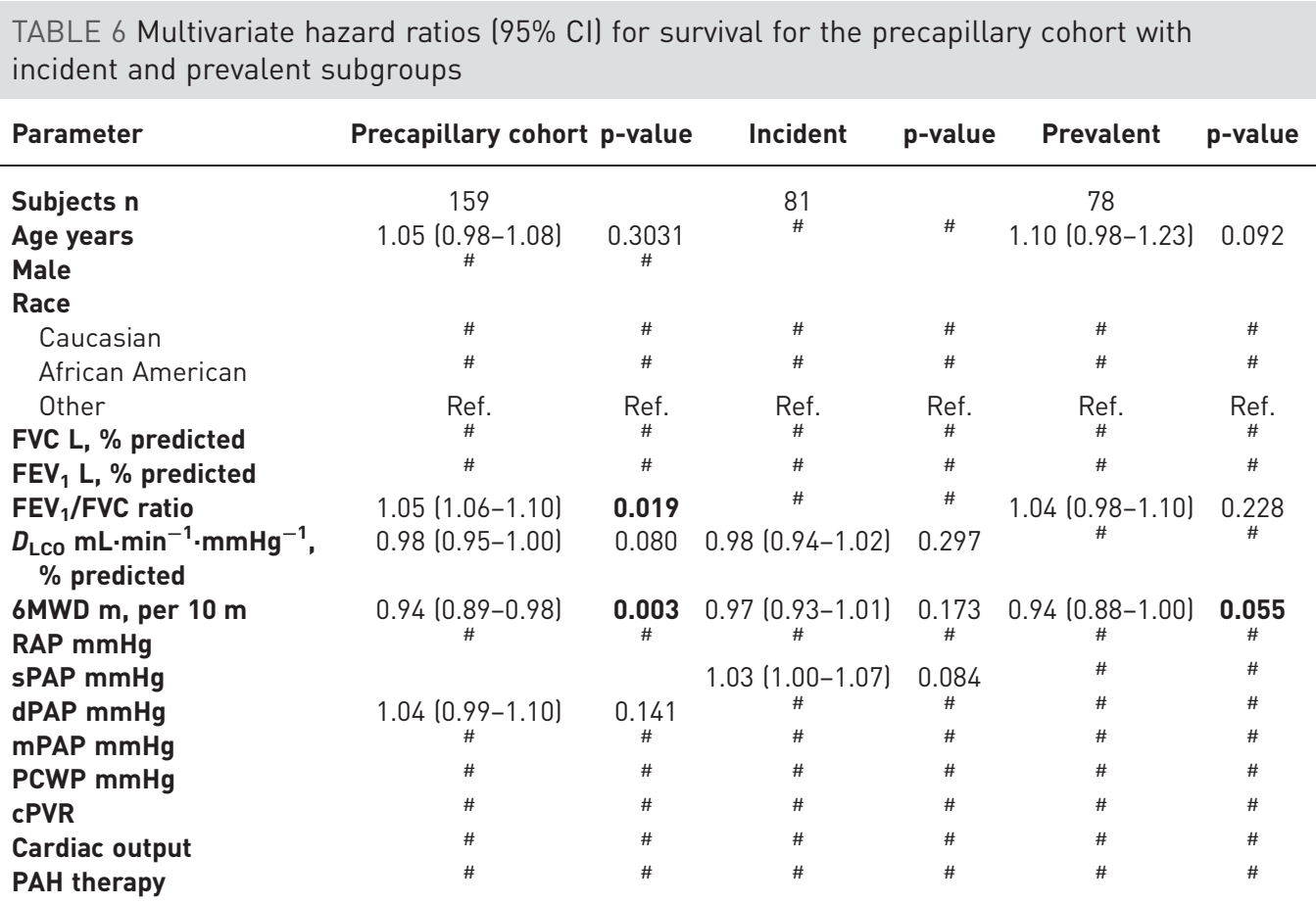

Bold type represents statistical significance. Statistically significant univariate hazard ratios were considered for the inclusion in multivariate models with $p<0.10$. For multivariate models, $p<0.05$ was considered statistically significant. For expected collinear terms (i.e. systolic pulmonary artery pressure (sPAP), diastolic pulmonary artery pressure (dPAP), mean pulmonary artery pressure (mPAP)), terms with the lowest p-value were deemed most statistically significant and included in multivariate models. FVC: forced vital capacity; $\mathrm{FEV}_{1}$ : forced expiratory volume in $1 \mathrm{~s} ; D_{\mathrm{LCO}}$ : diffusing capacity of the lung for carbon monoxide; 6MWD: 6-min walk distance; RAP: right atrial pressure; PCWP: pulmonary capillary wedge pressure; cPVR: calculated pulmonary vascular resistance; PAH: pulmonary arterial hypertension. \#: parameters not included in multivariate models based on $p>0.05$ in the univariate model.

specifically, only including patients with $\mathrm{mPAP} \geqslant 25 \mathrm{mmHg}$ in the registry and not allowing a wider spectrum of mPAP values might have muted any possible associations. Moreover, the fact that two-thirds of the patients were on PAH therapies might have further impacted any associations with outcomes. Interestingly, the French database, where even more patients were treated with PAH therapies, also failed to demonstrate an association between any haemodynamic parameter and survival [8].

Most patients in our cohort were treated with prednisone therapy. The treatment with anti-inflammatory medications has not demonstrated consistent benefit in SAPH, although response rates of $20-30 \%$ have been reported in small series [33]. Moreover, none of these studies included patients with stage IV fibrocystic disease, which represents the majority of the ReSAPH patient population. The use of steroid therapy was not associated with better outcomes in the ReSAPH nor French [8] registries.

In sarcoidosis, the presence of pulmonary hypertension is associated with decreased 6MWD $[5,9,30]$. In this analysis, the $6 \mathrm{MWD}$ was by far the strongest predictor of mortality, in the main cohort and both prevalent and incident subgroups. This association provides support for the use of the 6MWD as a functional and potentially modifiable surrogate end-point for future clinical trials in SAPH. Although some interventional studies of PAH therapies in patients with SAPH have failed to show a response in 6MWD to therapy $[35,38]$, there are other studies that attest to its utility as a responsive surrogate for therapeutic efficacy [27, 37].

In summary, this study is the largest registry to date of both incident and prevalent patients with precapillary SAPH. Although this analysis has inherent limitations of registry data including some missing data, it clearly demonstrates that functional impairment (as demonstrated by the 6MWD) and reduced diffusing capacity are associated with decreased survival in SAPH patients. The interesting association of an obstructive phenotype and improved outcomes has not been reported previously and needs to be examined further. Our description of outcomes in a diverse population of SAPH patients highlights a number of issues pertaining to this underappreciated entity that will hopefully form a foundation for future studies. Factors independently associated with outcomes included physiological $\left(\mathrm{FEV}_{1} / \mathrm{FVC}\right.$ ratio 
and diffusing capacity) and functional (6MWD) parameters. These same factors might help to inform future SAPH clinical trials with regards to enrichment ( $D_{\mathrm{LCO}}$ and $\mathrm{FEV}_{1} / \mathrm{FVC}$ ratio) and outcomes (6MWD).

Author contributions: S.D. Barnett, V. Kouranos, O.A. Shlobin and A.U. Wells performed all data analyses, and O.A. Shlobin was responsible for drafting the manuscript. O.A. Shlobin, V. Kouranos, R.P. Baughman, A.U. Wells and S.D. Nathan all provided significant input into the writing of the manuscript. All authors contributed to patient entry and supervising data entry at each of their sites. All authors reviewed the final manuscript.

Conflict of interest: O.A. Shlobin reports personal fees for consultancy from United Therapeutics, Bayer and Johnson \& Johnson, outside the submitted work. V. Kouranos has nothing to disclose. S.D. Barnett has nothing to disclose. E.H. Alhamad has nothing to disclose. D.A. Culver reports institutional funding for the registry from Gilead, during the conduct of the study; personal fees for advisory board work from Johnson and Johnson, outside the submitted work. J. Barney has nothing to disclose. F.C. Cordova has nothing to disclose. E.M. Carmona reports financial support for the clinical trial from Gilead, during the conduct of the study; personal fees for consultancy and developing education materials from CHEST, personal fees for editorial work from Elsevier, outside the submitted work. M.B. Scholand has performed advisory board work and been investigator in clinical trials for Boehringer Ingelheim and Genentech, and been investigator in clinical trials for Fibrogen and Global Blood Therapeutics, outside the submitted work; and has a patent Apparatus, Compositions and Methods for Assessment of Chronic Obstructive Pulmonary Disease Progression among Rapid and Slow Decline Conditions issued. M. Wijsenbeek has nothing to disclose. S. Ganesh has nothing to disclose. E.E. Lower reports grants from Gilead, Bayer and Genentech, during the conduct of the study. P.J. Engel has nothing to disclose. J. Wort reports grants and personal fees from Actelion Pharmaceuticals and Bayer Pharmaceuticals, personal fees from MSD, outside the submitted work. L. Price reports personal fees and education support from Actelion and Johnson \& Johnson, during the conduct of the study. A.U. Wells reports personal fees from Boehringer Ingelheim, Roche, Intermune and Bayer, outside the submitted work. S.D. Nathan reports personal fees for consultancy from United Therapeutics, Bayer Pharmaceuticals, Bellerophon and Actelion, during the conduct of the study. R.P. Baughman reports grants from Gilead, Bayer, Genentech, Foundation for Sarcoidosis Research and National Institutes of Health, grants and personal fees for consultancy from Actelion, grants and personal fees for consultancy and lectures from Mallinckrodt, during the conduct of the study.

Support statement: Gilead Pharmaceuticals provided an unrestricted educational grant to support the registry. The research database at the University of Cincinnati is funded by the National Institutes of Health (NIH) Clinical and Translational Science Award (CTSA) programme, grant 1UL1TR001425-01. The CTSA programme is led by the NIH's National Center for Advancing Translational Sciences (NCATS).

\section{References}

1 Baughman RP, Teirstein AS, Judson MA, et al. Clinical characteristics of patients in a case control study of sarcoidosis. Am J Respir Crit Care Med 2001; 164: 1885-1889.

2 Rybicki BA, Major M, Popovich J Jr, et al. Racial differences in sarcoidosis incidence: a 5-year study in a health maintenance organization. Am J Epidemiol 1997; 145: 234-241.

3 Baughman RP, Engel PJ, Taylor L, et al. Survival in sarcoidosis associated pulmonary hypertension: the importance of hemodynamic evaluation. Chest 2010; 138: 1078-1085.

4 Baughman RP, Field S, Costabel U, et al. Sarcoidosis in America. Analysis based on health care use. Ann Am Thorac Soc 2016; 13: 1244-1252.

5 Shorr AF, Helman DL, Davies DB, et al. Pulmonary hypertension in advanced sarcoidosis: epidemiology and clinical characteristics. Eur Respir J 2005; 25: 783-788.

6 Huitema MP, Bakker ALM, Mager JJ, et al. Prevalence of pulmonary hypertension in pulmonary sarcoidosis: the first large European prospective study. Eur Respir J 2019; 54: 1900897.

7 Shlobin OA, Nathan SD. Management of end-stage sarcoidosis: pulmonary hypertension and lung transplantation. Eur Respir J 2012; 39: 1520-1533.

8 Boucly A, Cottin V, Nunes $\mathrm{H}$, et al. Management and long-term outcomes of sarcoidosis-associated pulmonary hypertension. Eur Respir J 2017; 50: 1700465.

9 Handa T, Nagai S, Miki S, et al. Incidence of pulmonary hypertension and its clinical relevance in patients with sarcoidosis. Chest 2006; 129: 1246-1252.

10 Simonneau G, Robbins IM, Beghetti M, et al. Updated clinical classification of pulmonary hypertension. J Am Coll Cardiol 2009; 54: S43-S54.

11 Frost A, Badesch D, Gibbs JSR, et al. Diagnosis of pulmonary hypertension. Eur Respir J 2019; 53: 1801904.

12 Nunes H, Humbert M, Capron F, et al. Pulmonary hypertension associated with sarcoidosis: mechanisms, haemodynamics and prognosis. Thorax 2006; 61: 68-74.

13 Shlobin OA, Baughman RP. Sarcoidosis-associated pulmonary hypertension. Semin Respir Crit Care Med 2017; 38: $450-462$.

14 Baughman RP, Shlobin OA, Wells AU, et al. Clinical features of sarcoidosis associated pulmonary hypertension: results of a multi-national registry. Respir Med 2018; 139: 72-78.

15 Judson MA, Costabel U, Drent M, et al. The WASOG sarcoidosis organ assessment instrument: an update of a previous clinical tool. Sarcoidosis Vasc Diffuse Lung Dis 2014; 31: 19-27.

16 Obeid JS, McGraw CA, Minor BL, et al. Procurement of shared data instruments for Research Electronic Data Capture (REDCap). J Biomed Inform 2013; 46: 259-265.

17 von Elm E, Altman DG, Egger M, et al. The Strengthening the Reporting of Observational Studies in Epidemiology (STROBE) statement: guidelines for reporting observational studies. J Clin Epidemiol 2008; 61: 344-349.

18 Scadding JG. Prognosis of intrathoracic sarcoidosis in England. A review of 136 cases after five years' observation. Br Med J 1961; 2: 1165-1172. 
19 Hunninghake GW, Costabel U, Ando M, et al. ATS/ERS/WASOG statement on sarcoidosis. American Thoracic Society/European Respiratory Society/World Association of Sarcoidosis and other Granulomatous Disorders. Sarcoidosis Vasc Diffuse Lung Dis 1999; 16: 149-173.

20 Borg G. Psychophysical bases of perceived exertion. Med Sci Sports Exerc 1982; 14: 377-381.

21 Shorr AF, Davies DB, Nathan SD. Predicting mortality in patients with sarcoidosis awaiting lung transplantation. Chest 2003; 124: 922-928.

22 Arcasoy SM, Christie JD, Pochettino A, et al. Characteristics and outcomes of patients with sarcoidosis listed for lung transplantation. Chest 2001; 120: 873-880.

23 Bourbonnais JM, Samavati L. Clinical predictors of pulmonary hypertension in sarcoidosis. Eur Respir J 2008; 32: 296-302.

24 Nardi A, Brillet P-Y, Letounmelin P, et al. Stage IV sarcoidosis: comparison of survival with the general population and causes of death. Eur Respir J 2011; 38: 1368-1373.

25 Alhamad EH, Idrees MM, Alanezi MO, et al. Sarcoidosis-associated pulmonary hypertension: clinical features and outcomes in Arab patients. Ann Thorac Med 2010; 5: 86-91.

26 Głuskowski J, Hawryłkiewicz I, Zych D, et al. Pulmonary haemodynamics at rest and during exercise in patients with sarcoidosis. Respiration 1984; 46: 26-32.

27 Keir GJ, Walsh SL, Gatzoulis MA, et al. Treatment of sarcoidosis-associated pulmonary hypertension: a single centre retrospective experience using targeted therapies. Sarcoidosis Vasc Diffuse Lung Dis 2014; 31: 82-90.

28 Kirkil G, Lower EE, Baughman RP. Predictors of mortality in sarcoidosis. Chest 2018; 153: 105-113.

29 Patel MB, Mor-Avi V, Murtagh G, et al. Right heart involvement in patients with sarcoidosis. Echocardiography 2016; 33: 734-741.

30 Sulica R, Teirstein A, Kakarla S, et al. Distinctive clinical, radiographic and functional characteristics of patients with sarcoidosis-related pulmonary hypertension. Chest 2005; 128: 1483-1489.

31 Baughman RP, Gerson M, Bosken CH. Right and left ventricular function at rest and with exercise in patients with sarcoidosis. Chest 1984; 85: 301-306.

32 Hoeper MM, Behr J, Held M, et al. Pulmonary hypertension in patients with chronic fibrosing idiopathic interstitial pneumonia. PLoS One 2015; 10: e0141911.

33 Rodman DM, Lindenfeld J. Successful treatment of sarcoidosis-associated pulmonary hypertension with corticosteroids. Chest 1990; 97: 500-502.

34 Fisher KA, Serlin DM, Wilson KC, et al. Sarocidosis-associated pulmonary hypertension: outcome with long-term epoprostenol treatment. Chest 2006; 130: 1481-1488.

35 Baughman RP, Judson MA, Lower EE, et al. Inhaled iloprost for sarcoidosis associated pulmonary hypertension. Sarcoidosis Vasc Diffuse Lung Dis 2008; 26: 110-120.

36 Millman $\mathrm{N}$, Burton $\mathrm{CM}$, Iversen $\mathrm{M}$, et al. Pulmonary hypertension in end-stage pulmonary sarcoidosis: therapeutic effect of sildenafil? J Heart Lung Transplant 2008; 75: 329-334.

37 Barnett CF, Bonura EJ, Nathan SD, et al. Treatment of sarcoidosis-associated pulmonary hypertension: a two-center experience. Chest 2009; 135: 1455-1461.

38 Baughman RP, Culver DA, Cordova FC, et al. Bosentan for sarcoidosis-associated pulmonary arterial hypertension (BoSAPAH): a double blind, placebo controlled trial. Am J Resp Crit Care Med 2012; 185: A3639.

39 Benza RL, Miller DP, Barst RJ, et al. An evaluation of long-term survival from time of diagnosis in pulmonary arterial hypertension from the REVEAL Registry. Chest 2012; 142: 448-456. 